Ann.Rep. Asahikawa

Med. Coll.

1996. Vol.17, 15 27

\title{
Developing Presentation Skills
}

\author{
Simon Bayley
}

\section{Background}

The staff of Asahikawa Medical College are often asked to give presentations, either in Japan or abroad, in English. I have been approached on a number of occasions to check the English in proposed speeches and to give some coaching in presenting the material in either a poster presentation or before an audience of peers at a conference. I have also attended conferences where, in some cases, the standard of presentation, by both Japanese and non-Japanese presenters, did not do justice to the materials being presented. This is not surprising: public speaking, like teaching, counseling, driving a car or any other skill, is not an innate ability, and yet it is of ten assumed that being able to hold an audience's attention, present information and in some way change that audience requires no training. It is difficult enough to do this in one's first language, in a second language it is more so. For these reasons I organised a special course in presentations skills, which is run once a year in Asahikawa Medical College.

The course is short in length, in part because those attending are busy with their work in the college, and partly because it is intended that techniques discussed in the classes should be practised at home. To achieve excellence in a presentation takes a lot of practice and thought, but to improve on a poor or mediocre standard is relatively easy once awareness of the requirements has been developed.

The following report is based on the curriculum for the course. It is intended be prescriptive, with the aim of helping other teachers who may be planning to run a similar course in giving presentations, and also descriptive, for the benefit of those more interested in improving their own presentation skills. The course, and this report, attempts to touch on all aspects of giving a presentation, from 
preparing materials to developing breathing, from pronunciation to psychological preparation.

Technical or medical English terms are almost entirely absent from the content of the course. The course does not set out to teach English but to help the course participants to make best use of the materials they use.

Throughout this report, the word students is used for those attending the course, even though the participants would not be classified as such in any broader sense.

\section{Content and Delivery}

Competent and effective presentation can have a tremendous effect on the way an audience receives and reacts to information. It has been estimated that in America an initial impression of another person is based on three factors: how the person looks, how he sounds and what he says, with percentages of $55 \%$, $38 \%$ and a mere $7 \%$, respectively! The initial impression,though, is very important and when a presenter has only five or ten minutes to convey his information, the audience may not have time to revise their first impression. If the projection of information is inadequate then the information may get lost. A prime example is that of Alexander Fleming who shared the Nobel prize for the discovery of penicillin, the first antibiotic; despite the fact that his findings were so momentous, and caused a revolution in medical treatment, his first announcement of the discovery was largely ignored by the medical world as his lecture was so poor.

With any presentation, in a first language or second, there are three main areas to address to ensure success.

1. Content: what the speaker says, the text of the presentation.

2. External representation: how the presentation is heard and seen by the audience.

3. Internal representation: how giving a presentation is perceived by the speaker him or herself.

The distinctions between these areas are not clearly marked, and they are interdependant; changes in any one area will have an effect on the other areas, and affect the way that the information presented is perceived and processed by the listener. 
Raising Awareness

It is often the case that presenters or prospective presenters have never thought about a presentation as being anything more than reading aloud a text and then fielding questions. The first task,therefore, is to raise awareness and encourage analysis of presentation skills This is done on the course first through watching, on video, a presentation which is deliberately poor; students discuss their reactions to the material and try to analyse the presenters performance. The second task is for the students to assess their own attitudes to preparing for and giving presentations. This is done with a short questionnaire (App.I) . Intensive discussion always follows on from this quiz, and students begin to develop an understanding of the many factors to be considered in presenting their information before an audience.

\section{Content}

It must be assumed that the students' level of English is adequate for the presentation they intend to give; developing knowledge of language structure or lexis does not fall within the scope of such a short course. However, certain elements of presentation construction have to be addressed. It must be stressed that the text for a presentation is not the same as the paper on which it is based. Ideally, a speech would not be read at all, the use of cue cards being preferable, but to be realistic, the teacher on a course such as this has to accept that nearly all students will have to read their material from a script.

In a speech,the vocabulary and grammar is different in a number of ways from a written text; it is less impersonal, less objective, there is less use of the passive, etc. Moreover, the language used will change according to the object of the presentation. The subject may be the same but the presentation would be different according to whom is being addressed: peers with specialised knowledge, well-informed members of the public, special interest groups, representatives of business groups such as pharmaceutical companies, etc. It depends, too, on what the speaker wants from his audience: to inform them of his results, to enthuse them, or to persuade them contribute money to future projects.

One of the commonest criticisms of poor presentation is that the speaker tries to say too much in the time allowed. There is always information in a written paper that can be omitted from the text of speech without affecting its 
impact. If anybody in the audience feels it is important to know something that has been deliberately left out, then he or she can ask about it during the time given over to questions, and in any case, any over-editing will be noticed by the student's colleagues when practising the presentation. One way of presenting information that is omitted from the body of the text is by the use of slides.

Slides are a means of illustrating and supporting a talk but can be allowed to dominate the presentation. An inadequate presentation may include a series of slides, poorly designed and with too much information on them, which the presenter does little more than read aloud. Many students lack confidence in their presentation skill, especially their pronunciation, and try to compensate by showing the written word on the slide. This behaviour may have three unfortunate results: it distracts the presenter from the real task of improving his pronunciation; it prevents him from making, or even having to think about making, stimulating and effective visual aids; and it may risk irritating the audience.

\section{External representation}

This forms the body of the course, and is related to what the audience sees and hears. Is is mainly concerned with practising pronunciation and elements of prosody, such as stress and rhythm, but the speakers physical relationship to his audience is also touched upon.

Although not usually the cause of the greatest number of problems, pronunciation is perceived by the students as their major weakness. Compared with some speakers of English as a foreign language, the Japanese have relatively minor pronunciation problems, once the spoken model of the language, rather than that written in katakana is accepted. There are, though, some sounds that do present Japanese speakers of English with difficultise:
/1/as in light,fly
$/ \mathrm{r} /$ as in right,fry
$1 \theta /$ as in thin, method
$/ \partial /$ as they, bathe
/w/as in wood, woman
/s/as in sit,cinema
/z/as in zero,zip
etc,etc

Practice of these sounds is done through group drilling and repeating minimal pairs; students contrast, for example, light with right. Production and differentiation practice is done by each student with his or her partner. Students are also given longer utterances to practise the way that a sound changes 
according to its position or importance in a sentence: a phenomenon linked to sentence stress.

Most students are aware of word stress and it creates few problems for pronunciation. The role and use of sentence stress, however,is less understood and it is often poor awareness of this, weak forms and elision that cause word or phoneme pronunciation problems. Most students have some idea of the reasons for stress to highlight information, but do not use it, nor do they use weak forms. In the course, students are exposed to the way that stress affects rhythm and pronunciation through a number of exercises. In the following example, students are asked to mark the number and positions of the beats or stressed words:

cup coffee

cup of coffee

a cup of coffee

a large cup of coffee

have a large of coffee

Can I have a large cup of coffee

In each line,there are two beats, in the fourth line the stress shifts from 'cup' to 'large'. Even in the last line, there are still only two stresses, and two beats; saying this with the same two beats as in the first line may not be easy for speakers of a syllable-timed language but it forces students to use weak forms and elision. Jazz chants and nursery rhymes are also useful in practising these and other prosodic elements of speech. Students are given a rhyme or poem and have to mark the stressed and weak words or syllables on the paper before reading. Later, they are encouraged to mark stress on their own papers for presentation.

Students also do a number of exercises in contrastive stress. In the sentence 'John and Jane are flying to Tokyo on Monday', the primary stresses will change according to the context:

Who is going?

Jònn and Jàne are flying to Tokyo on Monday.

When?

John and Jane are flying to Tokyo on Monday

How are they going?

Jone and Jane are flỳing to Tokyo on Monday 
Is John or Jane going?

etc.

The use of stress has a great effect on the way information the speaker is presenting is perceived by the audience; information presented in a monotone hardly registers with most listeners. Other ways of making the voice more interesting, and the information more accessible, are appropriate uses of pace, volume, pausing, and emotional tone.

Good pacing of delivery often gets sacrificed for the need to present as much information as possible in the time allowed. It is of ten the case that a speaker may begin a presentation at a reasonable pace, only to increase speed as the presentation progresses. Again, presenters must be aware of the pace their speech, and how they can change that pace. Again, nursery rhymes are useful to provide practice.

I had a little nut tree,

Nothing would it bear,

But a silver nutneg,

And a golden pear.

Students practise saying this rhyme, with its other verses, saying the first three lines quickly, and the last line slowly, or vice versa.

Changing the volume of the voice also adds variety and colour to the presentation, but more effective is use of the pause. The pause is one of the most important ways to get attention; listeners are so used to people speaking that when there is a pause, everybody takes notice. A long pause at the end of a sentence can indicate a transition from one subject to another, while a shorter one, in mid-sentence, will signal emphasis. Students may recite the above rhyme again, but pausing before the last word; the word 'pear' immediately takes on a greater significance.

Even for a scientific paper, a neutral, unemotional tone is not normal. Like most people, each member of the audience would like to feel that he or she is being addressed by the speaker, rather then just listening to what could as easily be a tape tecording. The way information is received and processed is affected by emotion, any attitude suggested in the speaker's voice will have an influence on that emotion. Students practise putting emotional colour into their voice by simply taking any word - 'yesterday', 'in conclusion' or 'monoclonal' - and 
saying it as if they are surprised, thoughtful, about to reveal great news, about to share a secret, etc.

Combining all the above techniques to produce clear and stimulating delivery is difficult without practice, and correct breathing. Speaking in short phrases in normal discourse requires only short breaths, but in a presentation with longer utterances, and which may include polysyllabic technical terms, greater control of breathing is important. Breathing is, again like other features of giving presentations, an aspect that is largely taken for granted but which can be improved. The emotional tension that accompanies public speaking can have a strong influence on breathing and the voice; nervous speakers tend to take short, fast breaths yet a speaker cannot expect to have appropriate stress, rhythm and pronunciation if he is nearly panting.

During a presentation breathing should be through the mouth and from the diaphragm. Effort should be put into the exhalation, when the words are being formed, while the inhalation should be an almost automatic counteraction. It is not enough to just take three deep breaths before beginning the presentation, students need practice in improving breathing.

There are physical exercises that can be taught to improve breathing; these are designed to stretch the muscles that control the diaphragm rather than the muscles of the upper chest. For example, students stretch their arms, slowly, in an arc above the head whilst breathing through the mouth, first left arm then right. They are also encouraged to inhale and exhale using their diaphragm and to bring the air down to a point just above the navel. Breathing in this way they are asked to exhale as far as possible, hold their breath briefly using only their tummy muscles, and then relax and let their lungs fill up with air, without any conscious effort. Another exercise that trains the muscles of the diaphragm is one in which the students blow out repeatedly in short but hard breaths, again using the muscles of the tummy; the diaphragm will again seem to spring back without effort to bring in air.

Having done the physical exercises to develop breathing, students practise extending an utterance; again a nursery rhyme is used as a pattern. (Appendix II) The first line is spoken without a pause for breath, each successive line then has a phrase added. Breathing is through the mouth with effort put into exhaling, and between lines the intake of breath should be automatic. Stress is put on 
'This', nouns and verbs. Being able to say all the rhyme at a steady rate without feeling strain will probably take a lot of practise but it will be evidence of much more efficient breath control.

Breathing control is just one area where a lot can be achieved through a little thought and some effort, but practice is essential. Indeed all aspects of presentation explored on this course call for repeated practice, and all the features mentioned should be considered when writing the text for a speech. There is no reason why the text of the speech should look anything like the article on which it is based: the writing should be much bigger with double line spacing; sentence stresses and pauses can be marked on the paper; and lines should be broken not when they reach the right side of the page, but when a breath is to be taken.

In communicating information, the importance of delivery has been discussed. The speakers attitude to the audience, demonstrated through his physical behaviour, must also be taken into account. Generally, members of an audience want to be spoken to, not merely to be in a position to hear what is being said; a speaker must, therefore, look at his audience. A presenter who stands constantly with his head down cannot make contact with his listeners; one who stands with his back to the audience is actually sending the message, with his body, that he has little regard for his listeners. There is often no necessity for a presenter to look at his own slides or poster; the use of a light or rod pointer may sometimes be called for, but it should be done judiciously and from a position to one side of the diagram or picture. It would be preferable to make eye-contact with the listeners, but they must, at least, be given the respect of being faced when being spoken to.

\section{Internal Representation}

Even after extensive practice a student may still feel that his or her presentation will not be successful; he or she may feel too nervous. In the USA, popular surveys have shown that giving speeches in public is one of the most dreaded activities; it is unlikely that the average student is any different. This fear of speaking in public may have a number of sources.

Even the most experienced presenter, teacher or actor has the fear of giving a poor performance, but he uses the adrenaline it generates to improve his performance; the audience or students, though, are hardly aware of this fear. 
Everybody experiences this same kind of feeling, and the speaker should understand that it is a normal, and useful, reaction to the circumstances.

Some presenters feel intimidated by the audience. Probably each member of the audience is relieved that it is not himself that is standing at the front of the room. Perhaps the speaker needs reminding that some of the members of the audience are his friends, many more would like to be and all want to hear what the speaker has to say, or else they would not be present.

There may be a fear that the material is not good enough. This fear is unnecessary as, if it were the case, the speaker would not have been invited to speak. There may be many more experienced or learned people in the audience, but for the speaker's particular subject, he is the expert.

There are a number of ways to reduce the fear of giving a presentation. Foremost is practice; students must practise at every opportunity, on the course, before friends, in front of colleagues who will make constructive criticisms, to the student's own spouse and children. Preparation for the questions that follow the speech can more easily be anticipated by giving the speech to immediate colleagues, as well as those not already familiar with the details of the text, and inviting queries. Questions that follow the presentation may cause as much apprehension as giving the presentation itself; the question, in English, may not be fully understood or, at least, time to think of the answer may be needed. Students are shown how to gain thinking time by repeating or paraphrasing the question, with a request for confirmation of meaning, or by asking the questioner to do so.

Prospective speakers must think positively; what a person expects tends to happen. Many famous sportsmen use the technique of visualisation; before they run a race or play a tennis match they see, in their imagination, their performance and the result. On the course, students are asked to imagine themselves giving the speech. Some of the students begin to experience the same sense of nervousness, so they are asked to dissociate themselves from the picture, to watch themselves giving a speech as if they were watching a movie. Students can now run the movie as they want to watch it; they can make the picture larger or smaller, closer or further away, they can add a soothing soundtrack or an inspiring one, whichever they feel more comfortable with. They then run the movie to the conclusion they want, perhaps to the applause following their successful persentation. 
Often, the same people who are so nervous about standing in front of a room full of strangers to five a speech may be the most enthusiastic about doing just that in other contexts. In Japan, the obvious parallel is with singing karaoke. The two activities are comparable in many ways; the feelings generated by singing karaoke, or any other activity that involves excitement and adrenaline, for example, skiing or even driving, can be used to enhance performance in giving a presentation. The feelings associated with the enjoyable activity have to be transferred to the new activity of speaking before an audience. The responses generated by each activity are broken down into what the student sees, what he hears and what he feels. This process, which is taken, like the visualisation process above, from the applied psychology of Neuro-Linguistic Programming enables the student to be able to change his internal representation of the feared task so that its anticipation no longer causes discomfort. The exercise is not done on the course itself, but later, on a one to one basis, if both course teacher and student feel it is necessary. (Appendix III)

\section{Conclusion}

The amount of effort that goes into preparing a presentation depends on the student, but it will be small in comparison to the work carried out to obtain the material or data for the text of the speech. A small amount of effort in improving presentation skills can make a geat difference to way the way the information is received; it can make a speech interesting and the information, and the presenter, memorable for the audience.

The course in developing these skills is relatively short, and yet there are many areas that have to be covered. Therefore, the students have to practise the exercises and activities in their own time. They have to spend time writing and re-writing their presentation so that it is better suited to the spoken than the written word. It has to be rehearsed internally and practised in front of colleagues, friends even alone, and constructive criticism invited. It can be recorded on audio or videotape for self-criticism. All the points mentioned in this report have to be considered, step by step, with the teachers encouragement. For the teacher's part, the effort is less in actually teaching than in preparing good materials and explaining them clearly and with conviction; just like a good presentation. 
Appendix I : Course Questionnaire

Speech Quiz

Please read through this quiz. If you have any questions, ask the teacher. Then ask your partner the questions.

Partner's Name

1. The subject of my presentation is most important

2. I always think about the aim of my presentation

3 . The audience is most important

4. There are, basically, no differences between my presentation and the paper on which it is based.

5. For my visual aids I copy tables or diagrams from my paper

6 . I never have enough time for my presentation

7. I am always nervous when speaking in English in public

8. I speak clearly, not in a monotone

9. I prefer to read from a script

10. I always rehearse my presentation.

11. I maintain good eye-contact with my audience

12. I often feel stiff and unnatural

13. Many off the speeches I hear are boring, so probably mine is too.

14. I am nervous when giving a speech in Japanese

15. I feel disappointed if there are no questions at at the end of my presentations.

16. I dread the questions the most.

Now change partners. Then compare results with your partners: what is the best answer to each question?

\section{Appendix II : Breath Control}

Say each line without pausing for breath.

This is the house that Jack built. 
This is the malt that lay in the house that Jack built.

This is the rat that ate the malt that lay in the house that Jack built.

This is the cat that killed the rat that ate the malt that lay in the house that Jack built.

This is the dog that chased the cat that killed the rat that ate the malt that lay in the house that Jack built.

This is the cow with the crumpled horn that tossed the dog that chased the cat that killed the rat that ate the malt that lay in the house that Jack built.

This is the maiden all forlorn that milked the cow with the crumpled horn that tossed the dog that chased the cat that killed the rat that ate the malt that lay in the house that Jack built.

This is the man all tattered and torn that kissed the maiden all forlorn that milked the cow with the crumpled horn that tossed the dog that chased the cat that killed the rat that ate the malt that lay in the house that Jack built.

This is the priest all shaven and shorn that married the man all tattered and torn that kissed the maiden all forlorn that milked the cow with the crumpled horn that tossed the dog that chased the cat that killed the rat that ate the malt that lay in house that Jack built.

This is the cock that crowed in the morn that woke the priest all shaven and shorn that married the man all tattered and torn that kissed the maiden all forlorn that millked the cow with the crumpled horn that tossed the dog that chased the cat that killed the rat that ate the malt that lay in the house that Jack built.

This is the farmer sowing his corn that kept the cock that crowed in the morn that woke the priest all shaven and shorn that married the man all tattered and torn that kissed the maiden all forlorn that milked the cow with the crumpled horn that tossed the dog that chased the cat that killed the rat that ate the malt lay in the house that Jack built.

\section{Appendix III}

Changing the way the students feels about giving presentations; teacher and students work through the outline together. It presupposes that the teacher has some experience of Neuro-Linguistic Programming.

1. Think of some enjoyable and exciting experience; for example, singing karaoke. 
2. Think about how you imagine this activity in your mind. What do you see? Is the image large or small, near or far away? What can you hear? Where does the sound come from? Is it loud or soft? What are you saying to yourself? What can you feel? What is the temperature like? What can you feel?

3. Stop thinking about this, give your body a shake to break concentration on the activity.

4. Think now about giving a presentation. Go through the same questions as in Step 2.

5. Compare your experiences; notice the differences between what you enjoyed about the first experience and what you did not enjoy about giving the presentation, for each point.

6. For each point that is different, replace the negative feeling or image with the positive one until the prospect of giving a presentation begins to look, sound and feel like the prospect of singing karaoke.

\section{References}

Crystal, D., Cambridge Encyclopaedia of Language. CUP, 1987

Graham, C., Jazz Chants. OUP,1987

Grate, H.G., English Pronunciation Exercises Exercises for Japanese Students. Regents

Leeds, D., Powerspeak. Piatkus,1988

Mann, J., Murder, Magic and Medicine. OUP,1992

Mandell,S., Effective Presentation Skills. Crisp Publications, 1987

O’Connor, J. \& Seymour, J., Introducing NLP. Aquarian, 1990

Opie, I. \& P. Ed., The Oxford Dictionary of Nursery Rhymes. OUP, 1951

Raines, C., Visual Aids in Business. Crisp Publications, 1989

Settelen, P., Just Talk to Me. Thorsons, 1995

\section{Acknowledgements}

I would like to thank Dr Nina Hoque for starting my interest in this area, and to Dr Hiroko Hachizume and other members of the Pharmacology Department of Asahikawa Medical College for their support for my courses in developing presentation skills. 